\title{
Effect of nitroglycerin administration on cardio-ankle vascular index
}

This article was published in the following Dove Press journal:

Vascular Health and Risk Management

3 August 2016

Number of times this article has been viewed

\author{
Kazuhiro Shimizu' \\ Tomoyuki Yamamoto ${ }^{2,3}$ \\ Mao Takahashi' \\ Shuji Sato' \\ Hirofumi Noike' \\ Kohji Shirai \\ 'Department of Internal Medicine, \\ ${ }^{2}$ Department of Vascular Function, \\ Toho University Sakura Medical \\ Center, Chiba, ${ }^{3}$ Biological Information \\ Analysis Section, Fukuda Denshi Co., \\ Ltd, Tokyo, Japan
}

Correspondence: Kazuhiro Shimizu Department of Internal Medicine, Toho University Sakura Medical Center, 564-I Shimoshizu, Sakura-shi, Chiba 285-874I, Japan

Tel +814346288 II

Fax +8I 434628820

Email k432@sakura.med.toho-u.ac.jp
Purpose: The purpose of this study was to clarify the difference between effects of nitroglycerin (NTG) on the functional stiffness in patients with and without coronary artery disease (CAD) using a newly developed stiffness index, cardio-ankle vascular index (CAVI).

Subjects and methods: The two subject groups in this study were normal controls $(n=31)$ and CAD patients $(n=25)$. The normal controls had no medical history and were not on regular medications. On the other hand, the CAD patients had received various treatments like antihypertensive drugs, hypoglycemic agents, and statins. This study was conducted in CAD patients under medications. After a single sublingual administration of NTG $0.3 \mathrm{mg}$, CAVI, blood pressure (BP), and heart rate (HR) were measured every 5 minutes for 20 minutes. Comparisons of each parameter before and after taking NTG were evaluated for statistical significance using analysis of variance and post hoc tests. Tukey-Kramer test was used for post hoc comparisons.

Results: In the normal controls, CAVI significantly decreased from baseline after 5, 10, and 15 minutes (from $6.5 \pm 0.9$ to $5.2 \pm 0.9,5.5 \pm 0.9$, and $5.7 \pm 0.9$, respectively). Systolic BP and HR were not significantly changed. Diastolic BP significantly decreased from baseline after 5 and 10 minutes (from $72 \pm 8$ to $64 \pm 9$ and $63 \pm 9 \mathrm{mmHg}$, respectively). On the other hand, CAVI, HR, and diastolic BP were not changed significantly in CAD patients. Systolic BP was significantly decreased from baseline after 5,10 , and 15 minutes (from $147 \pm 16$ to $131 \pm 14,129 \pm 12$, and $129 \pm 13 \mathrm{mmHg}$, respectively). In the comparison of the two groups, $\Delta$ CAVI was not significantly different between the normal controls and CAD patients $(-1.4 \pm 0.7 \mathrm{vs}-1.4 \pm 0.9,-1.1 \pm 0.7 \mathrm{vs}$ $-1.4 \pm 1.0,-0.8 \pm 0.7$ vs $-1.2 \pm 1.0$, and $-0.5 \pm 0.7$ vs $-1.1 \pm 1.0$ at $5,10,15$, and 20 minutes, respectively). $\Delta \mathrm{HR}$ was not significantly different between the two groups. $\Delta$ Systolic BP in the CAD patients was significantly higher than in the normal controls at 5, 10, 15, and 20 minutes (normal controls vs $\mathrm{CAD} ;-3 \pm 7$ vs $-10 \pm 11,-3 \pm 5$ vs $-10 \pm 11,-3 \pm 6$ vs $-13 \pm 10$, and $-1 \pm 6$ vs $-11 \pm 10$ $\mathrm{mmHg}$, respectively). $\triangle$ Diastolic BP in the normal controls was significantly higher than in the CAD patients at 5 and 10 minutes (normal controls vs CAD; $-8 \pm 6$ vs $-4 \pm 4$ and $-9 \pm 4$ vs $-6 \pm 5$ $\mathrm{mmHg}$, respectively).

Conclusion: After NTG administration, the stiffness of the arteries from the origin of the aorta to the ankle as measured by CAVI decreased in both the normal controls and CAD patients, indicating that the response of arterial smooth muscle cells to nitric oxide is preserved even in CAD patients under medication.

Keywords: arterial stiffness, cardio-ankle vascular index, nitroglycerin, nitric oxide, stiffness parameter 


\section{Introduction}

Arterial stiffness affects the homeostasis of a living body, in which the vasodilation effect of nitric oxide (NO) plays a vital role. The salutary effects of nitroglycerin (NTG) in patients with angina pectoris are thought to be the result of the widespread action of the drug as a smooth muscle vasodilator. ${ }^{1}$ This vasodilation effect operates in the coronary artery and in systemic veins to induce pooling. It has been suggested that NTG may increase distensibility of peripheral muscular arteries and reduce systemic resistance; this action would explain the manner by which NTG reduces myocardial oxygen need and relieves the symptoms. ${ }^{1-4}$ However, the effects of NTG on the arterial stiffness of the arteries from the origin of the aorta to the ankle have not been quantitatively evaluated. As a method for quantitative assessment of arterial stiffness, pulse wave velocity (PWV) has been used for the last several decades and it was thought to be a kind of surrogate marker of arteriosclerosis; ${ }^{5-9}$ however, PWV depends inherently on blood pressure (BP) changes at the time of measurement. ${ }^{10}$ Therefore, there had been difficulties in interpreting the data dealing with various therapies or conditions associated with BP changes. ${ }^{11-16}$

In 2006, the cardio-ankle vascular index (CAVI) was developed as an arterial stiffness index, which was derived from the stiffness parameter beta theory with the application of the Bramwell-Hill equation., ${ }^{5,6,17}$ It is essentially independent from BP at the time of measurement. ${ }^{18,19} \mathrm{CAVI}$ increases with aging, ${ }^{20}$ and it is enhanced in arteriosclerotic patients with coronary artery disease (CAD), ${ }^{21-23}$ cerebral infarction, ${ }^{24,25}$ and chronic kidney diseases. ${ }^{26} \mathrm{CAVI}$ is also enhanced in patients with coronary risk factors such as hypertension, diabetes mellitus, smoking, and sleep apnea syndrome; it can be decreased by the treatment of these risks. ${ }^{27-35}$ Thus, CAVI has become established as a marker of arteriosclerosis. The stiffness shown by CAVI is thought to comprise organic stiffness and functional stiffness. ${ }^{36}$ Organic stiffness is mainly concerned with collagen, elastin, and hyaluronic acid, whereas functional stiffness is mainly smooth muscle cell contraction. ${ }^{37}$ Functional stiffness has been demonstrated using the $\alpha 1$-adrenoceptor blocker doxazosin, which dilates peripheral arteries and decreases BP. When doxazosin was administered to men, BP as well as CAVI decreased, indicating that CAVI was reflecting the degree of smooth muscle contraction of the arteries. ${ }^{19} \mathrm{Chiba}$ et al reported that NTG decreased CAVI in rabbits. ${ }^{38}$ They inserted a catheter in healthy rabbits' arteries directly and developed the system that measured CAVI every 1 minute. Intravenous infusion of NTG significantly decreased CAVI, which returned to the predrug control values immediately after stopping the infusion.

The purpose of this study was to clarify the difference between effects of NTG on the functional stiffness in patients with and without CAD using the newly developed stiffness index CAVI.

\section{Methods \\ Subjects}

The normal controls were 31 healthy volunteers (males 21; females 10) aged 24-50 years (mean \pm standard deviation [SD], 31.1 \pm 1.3 years), who came to our institute responding to our public announcement. They had no medical history and were not on regular medications. The CAD subjects were 25 patients (males 20; females 5) aged 60-84 years (mean \pm SD, $73.0 \pm 5.9$ years). The CAD patients comprised 19 with angina pectoris and six with old myocardial infarction; 17 patients underwent percutaneous coronary intervention, and eight patients had coronary artery bypass grafting. Blood sampling was performed after fasting for 12 hours. The details of baseline clinical characteristics are shown in Table 1.

Each participant gave written informed consent after receiving a detailed description of the procedures in accordance with the Declaration of Helsinki; the study was reviewed and approved by the Ethics Committee of Toho University.

\section{Experimental methods and design}

The CAD patients continued taking their daily medications during the course of the study. The study was conducted in a quiet and temperature-controlled room $\left(25^{\circ} \mathrm{C}-26^{\circ} \mathrm{C}\right)$. The subjects were studied at approximately the same time of day after a standardized light meal and were asked to avoid caffeine or tobacco on the day of the study. After resting for 10 minutes in supine position on a bed, CAVI was measured at baseline. Next, a tablet of NTG $(0.3 \mathrm{mg})$ was administered sublingually and CAVI was measured every 5 minutes for 20 minutes using a Vasela 1500 (Fukuda Denshi Co., Ltd, Tokyo, Japan). Simultaneously, BP and heart rate (HR) were measured using Vasela 1500.

\section{Statistical analysis}

Data were expressed as mean $\pm \mathrm{SD}$. Comparisons of each parameter before and after taking NTG were evaluated for statistical significance by analysis of variance and post hoc tests. Tukey-Kramer test was used for post hoc comparisons. To analyze the difference between the two groups, Student's unpaired $t$-test was used. $P$-value $<0.05$ was considered sig- 
Table I Characteristics of the subjects

\begin{tabular}{|c|c|c|c|}
\hline & $\begin{array}{l}\text { Normal } \\
\text { controls } \\
(n=3 I)\end{array}$ & $\begin{array}{l}\text { CAD } \\
\text { patients } \\
(n=25)\end{array}$ & $P$-value \\
\hline Sex (male/female) & $21 / 10$ & $20 / 5$ & NS \\
\hline Age (years) & $31.1 \pm 1.3$ & $73.0 \pm 5.9$ & $<0.001$ \\
\hline Height (cm) & $166.9 \pm 1.7$ & $163.3 \pm 7.2$ & NS \\
\hline Body weight (kg) & $61.8 \pm 1.7$ & $67.1 \pm 10.0$ & $<0.05$ \\
\hline Body mass index $\left(\mathrm{kg} / \mathrm{m}^{2}\right)$ & $22.1 \pm 0.3$ & $25.1 \pm 2.4$ & $<0.001$ \\
\hline $\mathrm{SBP}(\mathrm{mmHg})$ & $|I 7 \pm I|$ & $142 \pm 20$ & $<0.001$ \\
\hline $\mathrm{DBP}(\mathrm{mmHg})$ & $72 \pm 8$ & $85 \pm 12$ & $<0.001$ \\
\hline Heart rate (beats/min) & $65 \pm 9$ & $71 \pm 16$ & NS \\
\hline CAVI & $6.5 \pm 0.9$ & $10.3 \pm 1.0$ & $<0.001$ \\
\hline $\mathrm{HbAlc}(\%)$ & $4.8 \pm 0.2$ & $6.6 \pm 1.1$ & $\mathrm{P}<0.00 \mathrm{I}$ \\
\hline HDL cholesterol (mg/dL) & $66 \pm 12$ & $50 \pm 15$ & $<0.001$ \\
\hline LDL cholesterol (mg/dL) & $92 \pm 25$ & $89 \pm 21$ & NS \\
\hline Triglycerides (mg/dL) & $75 \pm 31$ & $142 \pm 39$ & $<0.001$ \\
\hline Creatinine (mg/dL) & $0.76 \pm 0.13$ & $1.00 \pm 0.37$ & $<0.01$ \\
\hline Uric Acid (mg/dL) & $5.9 \pm 1.5$ & $5.4 \pm 1.8$ & NS \\
\hline \multicolumn{4}{|l|}{ Medical history } \\
\hline Hypertension & $0(0)$ & $25(100)$ & $<0.001$ \\
\hline Dyslipidemia & $0(0)$ & $23(92)$ & $<0.001$ \\
\hline Diabetes mellitus & $0(0)$ & $10(40)$ & $<0.001$ \\
\hline Sleep apnea syndrome & $0(0)$ & $12(48)$ & $<0.001$ \\
\hline Previous history of CAD & $0(0)$ & $25(100)$ & $<0.001$ \\
\hline $\mathrm{PCl} / \mathrm{CABG}$ & $0 / 0$ & $17 / 8$ & $<0.001$ \\
\hline Smoking (none/current) & $24 / 7$ & $24 / 1$ & $<0.001$ \\
\hline \multicolumn{4}{|l|}{ Medications at entry } \\
\hline Calcium antagonist & 0 & $14(56)$ & \\
\hline ARBs & 0 & $14(56)$ & \\
\hline$\alpha$-Blockers & 0 & $0(0)$ & \\
\hline$\beta$-Blockers & 0 & $6(24)$ & \\
\hline Diuretics & 0 & $7(28)$ & \\
\hline Statins & 0 & $22(88)$ & \\
\hline Insulin & 0 & $2(8)$ & \\
\hline Hypoglycemic agents & 0 & $10(40)$ & \\
\hline Nitrates & 0 & $8(32)$ & \\
\hline CPAP & 0 & II (44) & \\
\hline
\end{tabular}

Notes: The numbers in parentheses represent percentages. Data are presented as mean \pm SD. Unpaired Student's $t$-test was used to compare the two groups.

Abbreviations: $A R B$, angiotensin receptor blocker; $C A B G$, coronary artery bypass grafting; CAD, coronary artery disease; CAVI, cardio-ankle vascular index; CPAP, continuous positive airway pressure; DBP, diastolic blood pressure; HbAlc, glycated hemoglobin; HDL, high-density lipoprotein; LDL, low-density lipoprotein; NS, not significant; $\mathrm{PCl}$, percutaneous coronary intervention; SBP, systolic blood pressure; $\mathrm{SD}$, standard deviation.

nificant. All statistical analysis was double-sided. Statistical analysis was performed using SPSS software package (SPSS Inc., Chicago, IL, USA).

\section{Results}

The clinical background of the normal controls and CAD patients is listed in Table 1. Age, body mass index, systolic $\mathrm{BP}$, diastolic BP, and CAVI were significantly higher in the CAD patients than in the normal controls $(P<0.001)$. In addition, the CAD patients had higher glycated hemoglo- bin and triglyceride concentration, and lower high-density lipoprotein cholesterol level $(P<0.001)$. In these patients, $88 \%$ received treatment with statins; thus, low-density lipoprotein cholesterol level was not significantly different between the two groups. Creatinine was significantly higher in the CAD patients $(P<0.05)$. The CAD patients underwent polysomnography for sleep apnea syndrome screening as risk assessment; $48 \%$ had sleep apnea syndrome with apnea hypopnea index $\geq 20$, and $44 \%$ were receiving treatment with continuous positive airway pressure.

The changes in CAVI, HR, and systolic/diastolic BP in the normal controls due to the administration NTG $0.3 \mathrm{mg}$ are shown in Figure 1. CAVI significantly decreased from baseline after 5, 10, and 15 minutes (from 6.5 \pm 0.9 to $5.2 \pm 0.9$, 5.5 \pm 0.9 , and 5.7 \pm 0.9 , respectively). Systolic BP and HR were not significantly changed. Diastolic BP significantly decreased from baseline after 5 and 10 minutes (from $72 \pm 8$ to $64 \pm 9$ and $63 \pm 9 \mathrm{mmHg}$, respectively).

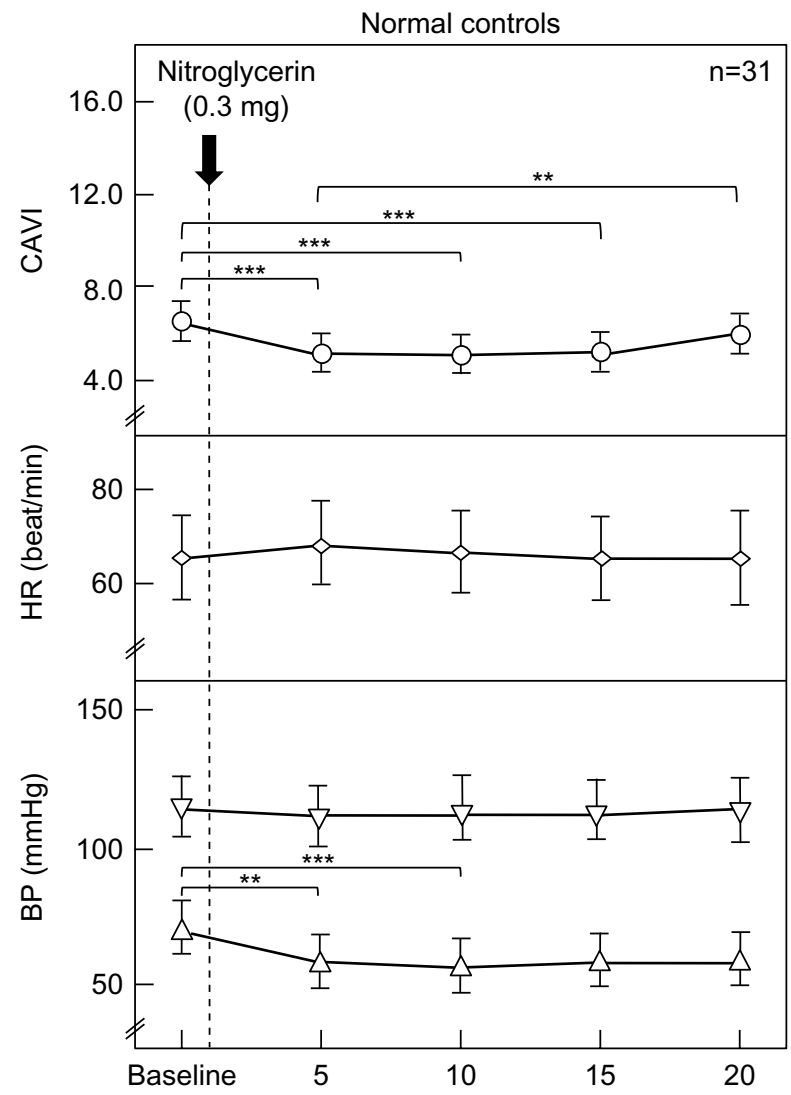

Figure I Changes in CAVI, HR, and BP after sublingual administration of nitroglycerin in normal controls $(n=31)$.

Notes: CAVI was measured using Vasela 1500 at baseline, 5, 10, 15, and 20 minutes after the administration of nitroglycerin $0.3 \mathrm{mg}$, and the value on the right side of CAVI was used. Data are presented as mean \pm standard deviation; $* * P<0.01$, and $* * * P<0.00$ I (Tukey-Kramer test was used for post hoc comparisons.)

Abbreviations: BP, blood pressure; CAVI, cardio-ankle vascular index, HR, heart rate. 
The changes in each parameter in the CAD patients due to the administration of NTG $0.3 \mathrm{mg}$ are shown in Figure 2. CAVI, HR, and diastolic BP were not changed significantly. Systolic BP was significantly decreased from baseline after 5,10 , and 15 minutes (from $147 \pm 16$ to $131 \pm 14,129 \pm 12$, and $129 \pm 13 \mathrm{mmHg}$, respectively).

The comparison of the difference $(\Delta)$ in each parameter between the two groups is shown in Figure 3. In the comparison of the two groups, $\triangle \mathrm{CAVI}$ was not significantly different between the normal controls and CAD patients $(-1.4 \pm 0.7$ vs $-1.4 \pm 0.9,-1.1 \pm 0.7$ vs $-1.4 \pm 1.0,-0.8 \pm 0.7$ vs $-1.2 \pm 1.0$, and $-0.5 \pm 0.7$ vs $-1.1 \pm 1.0$ at $5,10,15$, and 20 minutes, respectively). $\Delta \mathrm{HR}$ was not significantly different between the two groups. $\Delta$ Systolic BP in the CAD patients was significantly higher than in the normal controls at 5 , 10,15 , and 20 minutes (normal controls vs CAD; $-3 \pm 7$ vs $-10 \pm 11,-3 \pm 5$ vs $-10 \pm 11,-3 \pm 6$ vs $-13 \pm 10$, and $-1 \pm 6$ vs $-11 \pm 10$, respectively). $\Delta$ Diastolic $\mathrm{BP}$ in the normal controls was significantly higher than in the normal controls at 5 and

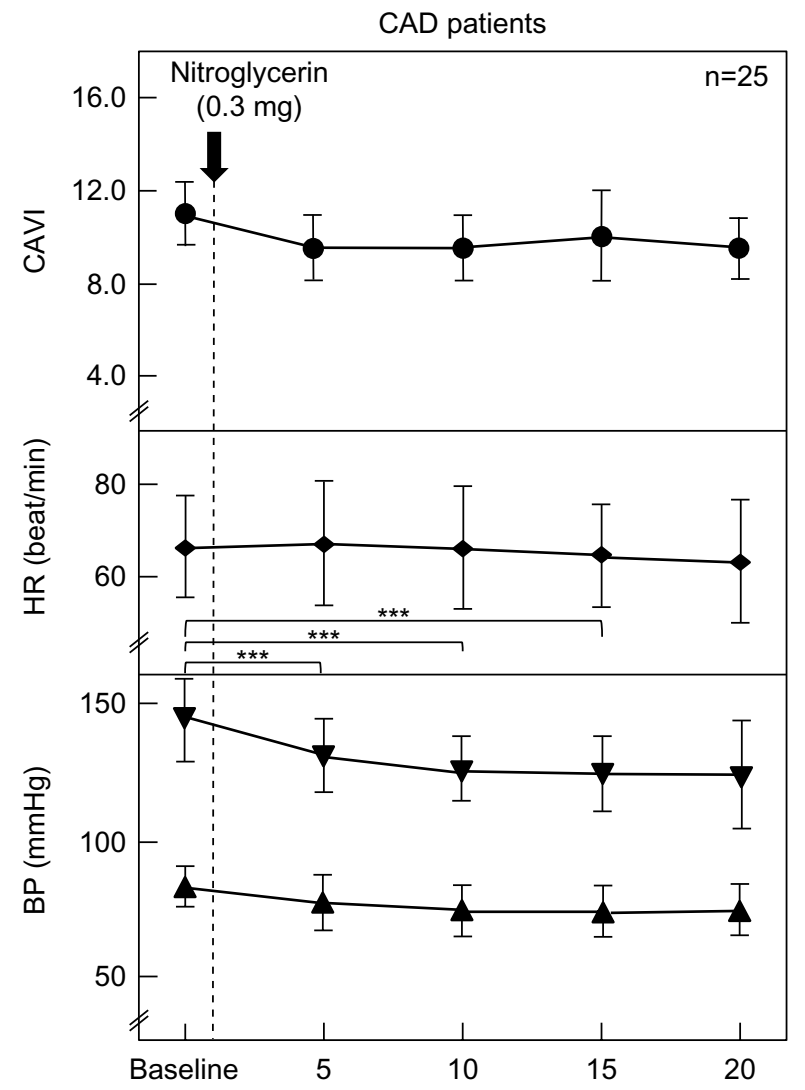

Figure 2 Changes in CAVI, HR, and BP after sublingual administration of nitroglycerin $0.3 \mathrm{mg}$ in CAD patents $(n=25)$.

Notes: Data are presented as mean \pm standard deviation; $* * * P<0.001$ (TukeyKramer test was used for post hoc comparisons).

Abbreviations: BP, blood pressure; CAD, coronary artery disease; CAVI, cardioankle vascular index; HR, heart rate.

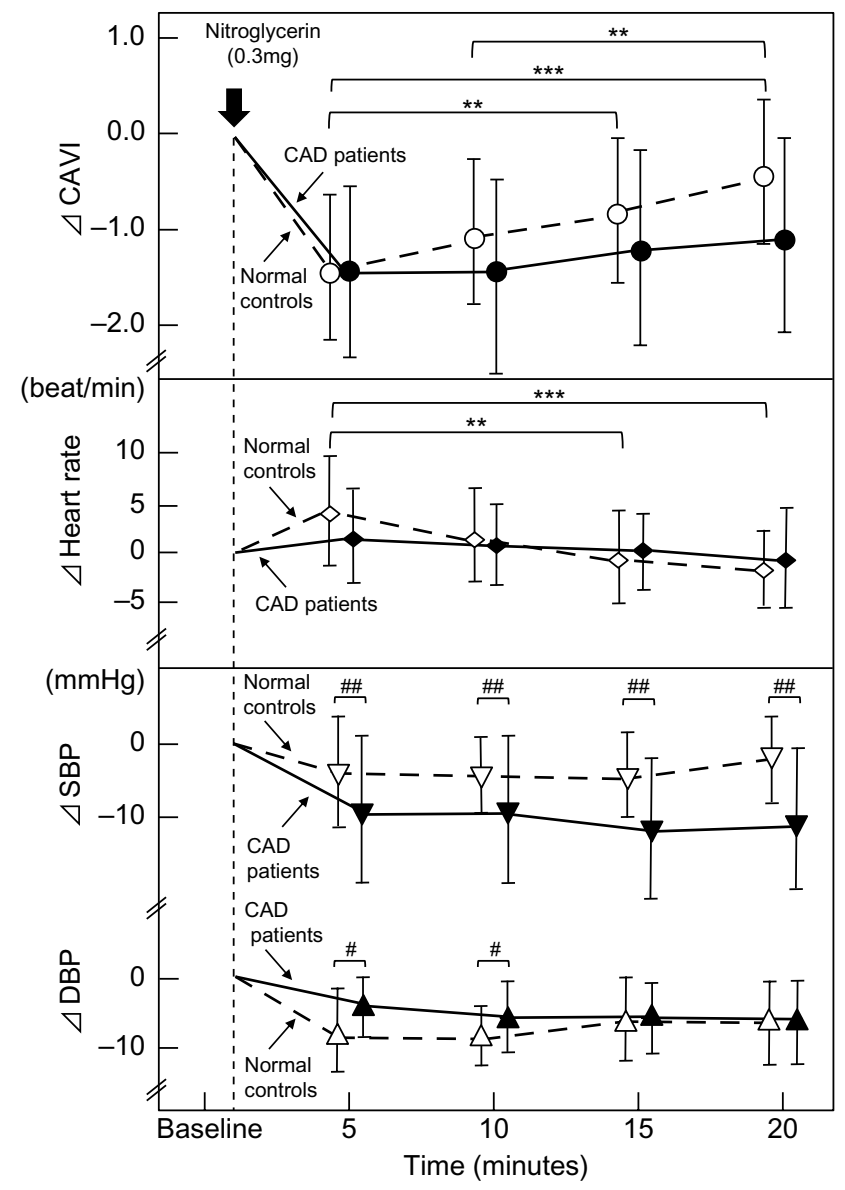

Figure 3 Comparison of $\Delta \mathrm{CAVl}, \Delta$ heart rate, and $\Delta$ blood pressure between normal controls and CAD patients during NTG administration.

Notes: $* * P<0.01$, and $* * * P<0.001$ (Tukey-Kramer test was used for post hoc comparisons); ${ }^{\#} P<0.05$ and ${ }^{\#} P<0.0$ I (unpaired Student's $t$-test was used to compare the two groups at each time). Data are presented as mean \pm SD.

Abbreviations: CAD, coronary artery disease; CAVI, cardio-ankle vascular index; DBP, diastolic blood pressure; NTG, nitroglycerin; SBP, systolic blood pressure; SD, standard deviation.

10 minutes (normal controls vs CAD: $-8 \pm 6$ vs $-4 \pm 4$ and $-9 \pm 4$ vs $-6 \pm 5$, respectively).

\section{Discussion}

To date, several reports have discussed the effect of NTG on arterial stiffness using PWV. ${ }^{39,40}$ However, as shown in the current study, BP decreased after NTG administration. Thus, even when PWV decreased, it cannot be concluded that NTG actually decreased arterial stiffness because PWV decreases when BP decreases. ${ }^{19}$ On the other hand, CAVI is independent of BP at the time of measurement. ${ }^{18,19}$ Taken together, the effects of the drugs that affect BP on proper arterial stiffness can be evaluated using CAVI. In this study, CAVI decreased in both the healthy young adults and CAD patients after NTG administration as shown in Figure 1 and 2, indicating that NTG decreased proper arterial stiffness of the artery from the origin of the aorta to the ankle. This is 
the first report to demonstrate the effect of NTG on proper arterial stiffness of the artery in vivo.

As to the mechanism of NTG, several hypotheses have been raised in the last 30 years. Generally, NTG dilates the coronary artery ${ }^{4}$ and increases coronary blood flow. ${ }^{41}$ However, Ogilvie reported that NTG has been demonstrated to possess unique vascular actions that dilate systemic venous vessels more potently than arterial vessels, leading to a reduction in cardiac output caused by the decreased venous return. ${ }^{42}$ The decreased CAVI in our study might indicate that NTG dilated the arterial tree composing the aorta, the so-called elastic artery, and the femoral and tibial arteries, the so-called muscular arteries. This dilation might facilitate decreasing afterload to the heart. Thus, NTG might decrease both the preload and afterload to the heart, and also relieve the stress to the heart muscles. It is also suggested that CAVI may be a useful index to at least partially express the afterload. This leads to the question of which artery might best respond to NTG, the aorta as an elastic artery or the femoral and tibial arteries as muscular arteries. Further precise studies are now under investigation.

In the comparison between the healthy volunteers and CAD patients, after NTG administration, $\triangle$ CAVI was not significantly different between the two groups.

Previously, there were some reports showing that vasodilator response to $\mathrm{NO}$ is maintained in CAD patients. Testa et al reported that vascular responses to NTG in patients with abnormal and normal findings on coronary angiograms were similar using blood flow velocity in the superficial femoral artery. ${ }^{43}$ Thanyasiri et al reported as to whether femoral vascular reactivity and/or fibrinolytic capacity are impaired in acute coronary syndrome patients over and above any dysfunction associated with stable CAD. ${ }^{44}$ They found that there was a significant impairment in large arterial endotheliumdependent dilatation in response to acetylcholine in both stable and acute coronary syndrome patients compared with control patients, whereas there was no significant difference in the response to NTG between the groups. These results indicate that NTG administration decreased the stiffness of the arteries from the origin of the aorta to the ankle in both the healthy volunteers and CAD patients to the same extent, which means that the response of arterial smooth muscle cells to $\mathrm{NO}$ was preserved even in CAD patients.

As shown in Figure 3, the decrease in systolic BP after the administration of NTG in the CAD patients was higher than that in the normal control group, while the decrease in diastolic BP in CAD patients was smaller than that in the normal control group. Arterial stiffness has a close relationship with diastolic BP. Moreover, arterial wall stiffness is a major determinant of left ventricular afterload. ${ }^{45}$ In CAD patients, arteriosclerotic states become worse with atherosclerotic changes compared to healthy volunteers. Diastolic BP might be difficult to decrease after the administration of NTG.

During the progression of arteriosclerosis, one of the major vascular qualitative changes is the calcification of arteries. Smooth muscle cells are even present in an advanced arteriosclerotic artery. Those smooth muscle cells were relaxed or became contractual functionally. It is difficult to distinguish this organic state and functional state strictly. But, we might be able to guess the organic stiffness as the baseline of CAVI, and functional stiffness as the rapid changed CAVI by NTG.

\section{Study limitations}

The CAD patients were examined under the controlled state of their various coronary risk factors. The fact that we cannot remove the effects of their medications is the limitation of our study.

\section{Conclusion}

After NTG administration, the stiffness of the arteries from the origin of the aorta to the ankle as measured by CAVI decreased in both the healthy volunteers and CAD patients at nearly the same extent, suggesting that the response of the arterial smooth muscle cells to NO is preserved even in CAD patients under medications.

\section{Acknowledgment}

The Department of Vascular Function was funded by Fukuda Denshi Co., Ltd.

\section{Disclosure}

Yamamoto T. is employed by Fukuda Denshi Co., Ltd., and was involved in the development of Vasera measuring CAVI. Shirai K. is a visiting professor of the Department of Vascular Function in Toho University, is supported by Fukuda Denshi Co., Ltd., but has no patent and no financial profit. The authors report no further conflicts of interest in this work.

\section{References}

1. Smulyan H, Mookherjee S, Warner RA. The effect of nitroglycerin on forearm arterial distensibility. Circulation. 1986;73: 1264-1269.

2. Ignarro LJ, Lippton H, Edwards JC, et al. Mechanism of vascular smooth muscle relaxation by organic nitrates, nitrites, nitroprusside and nitric oxide: evidence for the involvement of S-nitrosothiols as active intermediates. J Pharmacol Exp Ther. 1981;218: 739-749. 
3. McGregor M. Nitrates and myocardial ischemia. Circulation. 1982; 66:689-692.

4. Feldman RL, Pepine CJ, Conti CR. Magnitude of dilatation of large and small coronary arteries of nitroglycerin. Circulation. 1981;64(2):324-333.

5. Bramwell JC, Hill AV. The velocity of the pulse wave in man. Proc $R$ Soc Lond B. 1922;93(652):298-306.

6. Bramwell JC, Hill AV. Velocity of transmission of the pulse and elasticity of arteries. Lancet. 1922;1:891-892.

7. Hirai T, Sasayama S, Kawasaki T, Yagi S. Stiffness of systemic arteries in patients with myocardial infarction. Circulation. 1989;80(1): 78-86.

8. Asmar R, Benetos A, Topouchian J, et al. Assessment of arterial distensibility by automatic pulse wave velocity measurement: validation and clinical application studies. Hypertension. 1995;26(3):485-490.

9. Blacher J, Asmar R, Djane S, London GM, Safar ME. Aortic pulse wave velocity as a marker of cardiovascular risk in hypertensive patients. Hypertension. 1999;33(5):1111-1117.

10. Avolio AP, Chen SG, Wang RP, Zhang CL, Li MF, O'Rourke MF. Effects of aging on changing arterial compliance and left ventricular load in a northern Chinese urban community. Circulation. 1983;68(1): $50-58$.

11. Schulz E, Tsilimingas N, Rinze R. Functional and biochemical analysis of endothelial (dys)function and NO/cGMP signaling in human blood vessels with and without nitroglycerin pretreatment. Circulation. 2002; 105(10):1170-1175.

12. Fok H, Jiang B, Clapp B, Chowienczyk P. Regulation of vascular tone and pulse wave velocity in human muscular conduit arteries: selective effects of nitric oxide donors to dilate muscular arteries relative to resistance vessels. Hypertension. 2012;60(5):1220-1225.

13. Stewart AD, Millasseau SC, Kearney MT, Ritter JM, Chowienczyk PJ. Effects of inhibition of basal nitric oxide synthesis on carotid-femoral pulse wave velocity and augmentation index in humans. Hypertension. 2003;42(5):915-918.

14. Kinlay S, Creager MA, Fukumoto M, et al. Endothelium-derived nitric oxide regulates arterial elasticity in human arteries in vivo. Hypertension. 2001;38(5):1049-1053.

15. Kelly RP, Gibbs HH, O'Rourke MF, et al. Nitroglycerin has more favourable effects on left ventricular afterload than apparent from measurement of pressure in a peripheral artery. Eur Heart J. 1990;11(2): $138-144$.

16. Imaizumi T, Takeshita A, Ashihara T, Nakamura M. The effects of sublingually administered nitroglycerin on forearm vascular resistance in patients with heart failure and in normal subjects. Circulation. 1985;72(4):747-752.

17. Hayashi K, Handa H, Nagasawa S, Okumura A, Moritake K. Stiffness and elastic behavior of human intracranial and extracranial arteries. $J$ Biomech. 1980;13(2):175-184.

18. Shirai K, Utino J, Otsuka K, Takata M. A novel blood pressure-independent arterial wall stiffness parameter: cardio-ankle vascular index (CAVI). J Atheroscler Thromb. 2006;13(2):101-107.

19. Shirai K, Song M, Suzuki J, et al. Contradictory effects of $\beta 1$ - and $\alpha 1$-adrenergic receptor blockers on cardio-ankle vascular stiffness index (CAVI): CAVI is independent of blood pressure. JAtheroscler Thromb. 2011;18(1):49-55.

20. Namekata T, Suzuki K, Ishizuka N, Shirai K. Establishing baseline criteria of cardio-ankle vascular index as a new indicator of arteriosclerosis: a cross-sectional study. BMC Cardiovasc Disord. 2011;11:51.

21. Nakamura K, Tomaru T, Yamamura S, Miyashita Y, Shirai K, Noike $\mathrm{H}$. Cardio-ankle vascular index is a candidate predictor of coronary atherosclerosis. Circ J. 2008;72(4):598-604.

22. Yingchoncharoen T, Limpijankit T, Jongjirasiri S, Laothamatas J, Yamwong S, Sritara P. Arterial stiffness contributes to coronary artery disease risk prediction beyond the traditional risk score (RAMA-EGAT score). Heart Asia. 2012;4(1):77-82.

23. Izuhara M, Shioji K, Kadota S, et al. Relationship of cardio-vascular index (CAVI) to carotid and coronary arteriosclerosis. Circ J. 2008;72(11):1762-1767.
24. Suzuki J, Sakakibara R, Tomaru T, et al. Stroke and cardio-ankle vascular stiffness index. J Stroke Cerebrovasc Dis. 2011;22(2):171-175.

25. Choi SY, Park HE, Seo H, Kim M, Cho SH, Oh BH. Arterial stiffness using cardio-ankle vascular index reflects cerebral small vessel disease in healthy young and middle aged subjects. J Atheroscler Thromb. 2013;20(2):178-185.

26. Nakamura K, Iizuka T, Takahashi M, et al. Association between cardio-ankle vascular index and serum cystatin $\mathrm{C}$ levels in patients with cardiovascular risk factor. $J$ Atheroscler Thromb. 2009;16(4): 371-379.

27. Okura T, Watanabe S, Kurata M, et al. Relationship between cardioankle vascular index (CAVI) and carotid atherosclerosis in patients with essential hypertension. Hypertens Res. 2007;30(4):335-340.

28. Ibata J, Sasaki H, Kakimoto T, et al. Cardio-ankle vascular index measures arterial wall stiffness independent of blood pressure. Diabetes Res Clin Pract. 2008;80(2):265-270.

29. Nagayama D, Saiki A, Endo K, et al. Improvement of cardio-ankle vascular index by glimepiride in type 2 diabetic patients. Int J Clin Pract. 2010;64(13):1796-1801.

30. Kubozono T, Miyata M, Ueyama K, et al. Acute and chronic effects of smoking on arterial stiffness. Circ J. 2011;75(3):698-702.

31. Noike H, Nakamura K, Sugiyama Y, et al. Changes in cardioankle vascular index in smoking cessation. J Atheroscler Thromb. 2010;17(5):517-525.

32. Kumagai T, Kasai T, Kato M, et al. Establishment of the cardioankle vascular index in patients with obstructive sleep apnea. Chest. 2009;136(3):779-786.

33. Kato M, Kumagai T, Naito R, et al. Change in cardio-ankle vascular index by long-term continuous positive airway pressure therapy for obstructive sleep apnea. J Cardiol. 2011;58(1):74-82.

34. Kasai T, Inoue K, Kumagai $\mathrm{T}$, et al. Plasma pentraxin 3 and arterial stiffness in men with obstructive sleep apnea. Am J Hypertens. 2011;24(4):401-407.

35. Nagayama D, Endo K, Ohira M, et al. Effects of body weight reduction on cardio-ankle vascular index (CAVI). Obes Res Clin Pract. 2013;7(2):e139-e145.

36. Hayashi K, Yamamoto T, Takahara A, Shirai K. Clinical assessment of arterial stiffness with cardio-ankle vascular index: theory and applications. J Hypertens. 2015;33:1742-1757.

37. Zieman SJ, Melenovsky V, Kass DA. Mechanisms, pathophysiology, and therapy of arterial stiffness. Arterioscler Thromb Vasc Biol. 2005;25(5):932-943.

38. Chiba T, Yamanaka M, Takagi S, et al. Cardio-ankle vascular index (CAVI) differentiates pharmacological properties of vasodilators nicardipine and nitroglycerin in anesthetized rabbits. J Pharmacol Sci. 2015;128(4):185-192.

39. Wilkinson IB, Qasem A, McEniery CM, Webb DJ, Avolio AP, Cockcroft JR. Nitric oxide regulates local arterial distensibility in vivo. Circulation. 2002;105:213-217.

40. Bank AJ, Kaiser DR, Rajala S, Cheng A. In vivo human brachial artery elastic mechanics: effects of smooth muscle relaxation. Circulation. 1999;100(1):41-47.

41. Brachfeld N, Bozer J, Gorin R. Action of nitroglycerin on the coronary circulation in normal and in mild cardiac subjects. Circulation. 1959;19(5):697-704.

42. Ogilvie RI. Effect of nitroglycerin on peripheral blood flow distribution and venous return. J Pharmacol Exp Ther. 1978;207(2):372-380.

43. Testa M, Biasucci LM, Cacciola M, et al. Variable response of the peripheral circulation to acetylcholine in patients with coronary artery disease. Am J Cardiol. 1996;77(2):149-153.

44. Thanyasiri P, Celermajer DS, Adams MR. Endothelial dysfunction occurs in peripheral circulation patients with acute and stable coronary artery disease. Am J Physiol Heart Circ Physiol. 2005;289(2): H513-H517.

45. Schillaci G, Battista F, Settimi L, Anastasio F, Pucci G, et al. Cardioankle vascular index and subclinical heart disease. Hypertens Res. 2015;38(1):68-73. 
Vascular Health and Risk Management is an international, peerreviewed journal of therapeutics and risk management, focusing on concise rapid reporting of clinical studies on the processes involved in the maintenance of vascular health; the monitoring, prevention and treatment of vascular disease and its sequelae; and the involvement of metabolic disorders, particularly diabetes. This journal is indexed on PubMed Central and MedLine. The manuscript management system is completely online and includes a very quick and fair peer-review system, which is all easy to use. Visit http://www.dovepress.com/ testimonials.php to read real quotes from published authors. 